\title{
Fluoroscopy-guided simultaneous distal perfusion as a preventive strategy of limb ischemia in patients undergoing extracorporeal membrane oxygenation
}

\author{
Woo Jin Jang ${ }^{1}$, Yang Hyun Cho ${ }^{2}$, Taek Kyu Park ${ }^{3}$, Young Bin Song ${ }^{3}$, Jin-Oh Choi ${ }^{3}$, Joo-Yong Hahn ${ }^{3}$, \\ Seung-Hyuk Choi ${ }^{3}$, Hyeon-Cheol Gwon ${ }^{3}$, Eun-Seok Jeon ${ }^{3}$, Woo Jung Chun ${ }^{1}$, Ju Hyeon Oh ${ }^{1}$ \\ and Jeong Hoon Yang ${ }^{3^{*}}$
}

\begin{abstract}
Background: Limited data are available regarding prevention of limb ischemia in femorally cannulated patients on venoarterial extracorporeal membrane oxygenation (VA-ECMO). We investigated the association between strategy of distal perfusion catheter (DPC) insertion and vascular complications like limb ischemia in patients undergoing VA-ECMO.

Methods: We evaluated 230 patients from two tertiary hospitals who received VA-ECMO via femoral cannulation between August 2014 and July 2017. The patients were divided into two groups according to DPC insertion strategy: patients who underwent DPC insertion at the time of primary cannulation (DPC group, $n=96$ ) and patients who were provisionally treated with DPC (No-DPC group, $n=134$ ). The primary outcome was limb ischemia.

Results: Of the 96 patients in the DPC group, 61 (63.5\%) underwent insertion under fluoroscopic guidance. The DPC group had a significantly lower incidence of limb ischemia ( $2.1 \% \mathrm{vs.} 8.2 \%, p=0.047)$ and a lower tendency of in-hospital mortality (38.5\% vs. 50.7\%, $p=0.067$ ) than the No-DPC group. In the multivariable analysis, fluoroscopy-guided simultaneous insertion of the DPC (odds ratio $0.11 ; 95 \%$ confidence interval $0.01-0.98 ; p=0.048$ ) was a significant predictor of reduction of limb ischemia.
\end{abstract}

Conclusions: Simultaneous insertion of a DPC, particularly under fluoroscopy guidance, can be considered as a preventive strategy for limb ischemia in femorally cannulated patients on VA-ECMO.

Keywords: Distal perfusion catheter, Limb ischemia, Extracorporeal membrane oxygenation

\section{Background}

Venoarterial extracorporeal membrane oxygenation (VA-ECMO) has been widely used as a salvage therapy in critically ill patients with refractory cardiogenic shock

\footnotetext{
*Correspondence: jhysmc@gmail.com

${ }^{3}$ Division of Cardiology, Department of Critical Care Medicine and Medicine, Heart Vascular Stroke Institute, Samsung Medical Center, Sungkyunkwan University School of Medicine, 81, Irwon-dong, Gangnam-gu, Seoul 135-710, Republic of Korea

Full list of author information is available at the end of the article
}

[1]. The femoral vessel approach for VA-ECMO insertion is regarded as the default route because the equipment can be placed rapidly and easily [2]. In patients undergoing VA-ECMO using transfemoral cannulation, limb ischemia is a lethal complication that can be influenced by vessel size, increased vascular tone due to hemodynamic instability, size of the indwelling arterial cannula, and use of vasopressors [3-6]. To prevent limb ischemia after cannulation, the guidance of an antegrade distal perfusion catheter (DPC) into the proximal superficial femoral artery (SFA) has been assisted by various techniques such as ultrasound and fluoroscopy 
$[2,7]$. However, the optimal timing of and strategy for DPC insertion have not been fully elucidated for patients undergoing VA-ECMO via femoral cannulation. Therefore, we investigated whether simultaneous insertion of a DPC, particularly fluoroscopy-guided DPC insertion, at the time of primary ECMO cannulation can reduce critical limb ischemia compared with a provisional approach.

\section{Methods}

\section{Study population}

We investigated 257 consecutive patients who underwent VA-ECMO from a retrospective multicenter registry at Samsung Medical Center, Seoul, South Korea, and Samsung Changwon Hospital, Gyeongnam, South Korea, from August 2014 through July 2017. Of these, we included only patients who were placed on peripheral VA-ECMO via femoral cannulation and excluded patients who were under 18 years of age or who underwent ECMO using central aortic or axilla-arterial cannulation. Ultimately, 230 patients were enrolled in this study and were divided into two groups according to timing of DPC insertion: patients who underwent DPC insertion at the time of the primary cannulation (DPC group) and patients who did not undergo DPC insertion at the primary femoral cannulation including provisional DPC insertion after the onset of distal limb ischemia (NoDPC group) (Fig. 1). The local institutional review board of each participating hospital approved this study and waived the requirement for informed consent.

\section{Extracorporeal membrane oxygenation implantation and management}

The decision to implant ECMO was made by an experienced team, and the ECMO was placed by either cardiovascular surgeons or interventional cardiologists. The Capiox Emergency Bypass System (Capiox EBS ${ }^{\mathrm{TM}}$; Terumo, Inc., Tokyo, Japan) and Permanent Life Support (PLS) System (MAQUET, Rastatt, Germany) were used. Heparin was intravenously administered as a bolus of 5000 units, followed by continuous intravenous infusion to maintain an activated clotting time between 150 and $180 \mathrm{~s}$. After initiation of ECMO, the pump blood flow rate was initially set above $2.2 \mathrm{~L} / \mathrm{min} /$ body surface area $\left(\mathrm{m}^{2}\right)$ and subsequently adjusted to maintain a mean arterial pressure above $65 \mathrm{mmHg}$. Blood pressure was continuously monitored through an arterial catheter, and arterial blood gas analysis was performed in the artery of the right arm to estimate cerebral oxygenation. Additional fluids, blood transfusion, and/or catecholamines (i.e., norepinephrine, epinephrine, or dobutamine) were supplied to maintain intravascular volume and/or to achieve a mean arterial pressure above $65 \mathrm{mmHg}$ if necessary [8].

\section{Cannulation of extracorporeal membrane oxygenation and distal perfusion catheter}

Percutaneous cannulation of the femoral artery and vein was mainly performed by the attending staff interventional cardiologist or cardiovascular surgeon using the Seldinger technique. The femoral vessels (either unilateral, one-side arterial, or one-side venous) were accessed

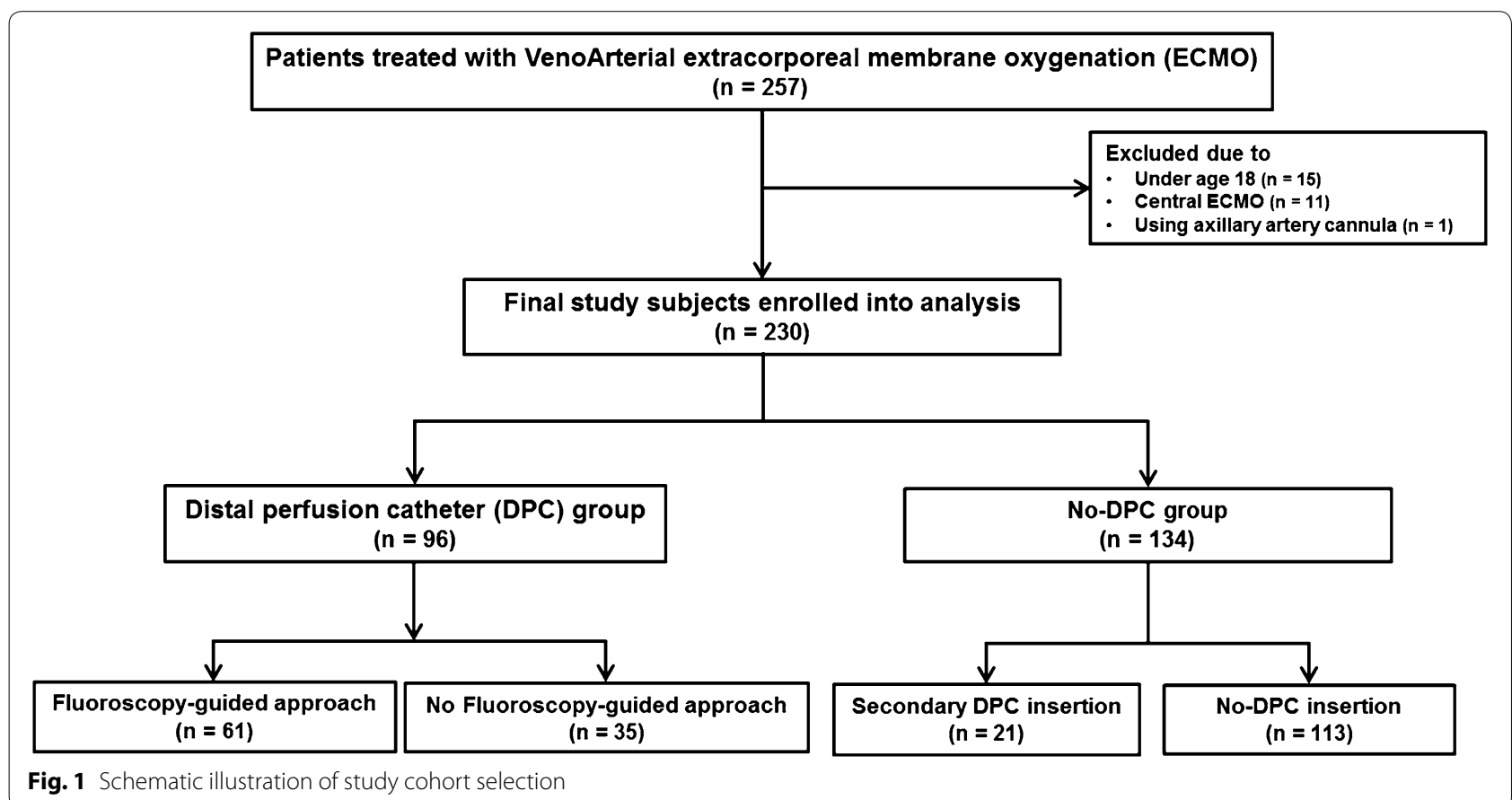


retrograde using an angiogram needle. The venous cannula was either 55 or $68 \mathrm{~cm}$ in length and from 21 to $28 \mathrm{Fr}$; the arterial cannula was $24 \mathrm{~cm}$ and from 14 to $21 \mathrm{Fr}$. The final selection of cannula was based on manufacturer pressure-flow curves for each cannula size and patient size. Femoral cut-down procedures were performed when it was difficult to puncture the femoral artery percutaneously, for example, in patients with peripheral artery disease or severe obesity. At bedside, the DPC placement site was accessed antegrade using a micropuncture needle followed by a 0.018-inch nitinol wire (Cook Medical Inc, Bloomington, IN, USA) at the proximal SFA ipsilateral to the arterial cannula. A 6- or 7-Fr. sheath was then advanced into the mid-SFA. In the catheterization laboratory, we first inserted another sheath at the common femoral artery (CFA) contralateral to the arterial ECMO cannula and advanced a hydrophilic wire from the CFA sheath (through the aortic bifurcation and the ipsilateral common iliac artery, then between the arterial ECMO cannula and the vessel wall of the ipsilateral common iliac artery) to the distal portion of the ipsilateral SFA. The DPC was then safely inserted into the distal portion of the arterial cannula (ipsilateral to the SFA) using a micropuncture needle as the reference point of the previously placed hydrophilic wire. The catheter was attached to the side port of the arterial cannula using 6-inch extension tubing with an intervening three-way stopcock (Fig. 2).

\section{Data collection, definitions, and study outcomes}

Baseline characteristics, procedural characteristics, laboratory data, and clinical outcome data were obtained by reviewing medical records or by telephone contact, if necessary. Laboratory findings, including creatinine and lactate, were collected just before VA-ECMO insertion. The primary outcome was limb ischemia, which was defined as cases requiring surgical management or involving neurologic sequelae. In-hospital mortality, successful weaning rate of ECMO, thrombotic events, major bleeding, and catheter-related complications (defined as a composite of limb ischemia, major bleeding, and thrombotic events) were assessed in addition to the primary outcome. Major bleeding was defined as cases involving hemodynamic instability or those that occurred in a critical area or organ such as intracranial, retroperitoneal, pericardial, or intramuscular with compartment syndrome.

\section{Statistical analysis}

Continuous variables were compared using Student's $t$ test or the Wilcoxon rank-sum test. The results were presented as mean \pm standard deviation or median with interquartile range. Categorical data were tested using Fisher's exact test or the Chi-square test. Multivariable logistic regression analysis was performed via a stepwise backward selection process to determine the independent predictors of limb ischemia. Clinical variables (i.e., fluoroscopy-guided simultaneous DPC, age $\geq 65$ years, gender, duration of ECMO $>5$ days, and large arterial cannula) were included in the regression models. All variables associated with limb ischemia were analyzed using univariate analysis. Factors with $p<0.2$ and those that were clinically relevant were included in the multivariable analysis. All tests were two-tailed, and $p$ value $<0.05$ was considered statistically significant. Statistical analyses were performed using SPSS software, version 23 (IBM, Armonk, New York, USA).

\section{Results}

Baseline, procedural, and laboratory characteristics

The baseline and procedural characteristics of the study population are shown in Table 1. There were no significant differences between the DPC group and the NoDPC group except body mass index (BMI) in baseline characteristics. Of the 134 patients in the No-DPC group, 21 (15.7\%) underwent secondary DPC insertion. ECMO was mainly inserted in either catheterization laboratory room, intensive care unit, or emergency room. Extracorporeal cardiopulmonary resuscitation (ECPR) was more frequently performed in the No-DPC group than in the DPC group $(p=0.003)$. The size of femoral arterial cannula was similar between the DPC group and the No-DPC group $(p=0.080)$, but venous cannular size was larger in the DPC group than in the No-DPC group $(p=0.019)$. Anticoagulation therapy $(p=0.004)$ and left ventricular venting during ECMO support $(p=0.029)$ were more frequently performed in the DPC group than in the No-DPC group, and large arterial cannula $(p=0.066)$ tended to be used less frequently in the DPC group compared to the No-DPC group. The median duration of ECMO support was 3 days [interquartile range (IQR) 1-7 days]. The median total length of stay in the intensive care unit was 6 days (IQR 1-16 days), and the median total length of stay in the hospital was 20 days (IQR 6-45 days).

\section{Limb ischemia and other catheter-related complications in VA-ECMO patients}

Thirty-four cases of ischemic complication (13 limb ischemia, 18 thrombotic events, and 3 ischemic strokes) occurred. Of the 13 patients with distal limb ischemia, 3 were recovered through medical treatment, while 3 

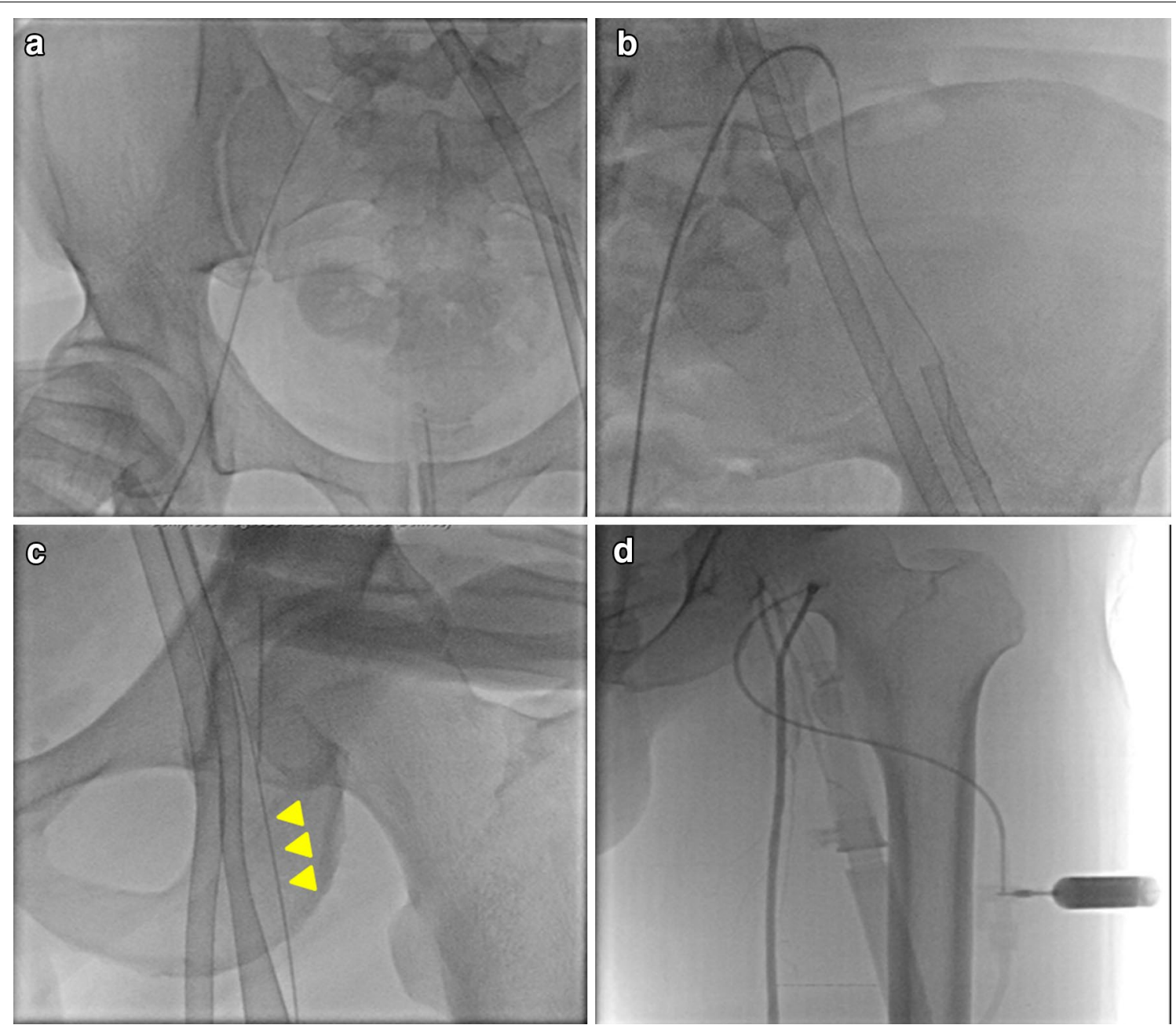

Fig. 2 Percutaneous insertion of a distal perfusion catheter. a Under fluoroscopy guidance, a sheath at the contralateral common femoral artery (CFA) was inserted using a micropuncture needle followed by a 0.018-inch nitinol wire. $\mathbf{b}$ A hydrophilic wire was advanced from the sheath of the contralateral CFA (through the aortic bifurcation and the ipsilateral common iliac artery, between the arterial ECMO cannula and the vessel wall of the ipsilateral common iliac artery) to the distal portion of the ipsilateral superficial femoral artery (SFA). c The proximal SFA ipsilateral to the arterial cannula was punctured using a micropuncture needle followed by a 0.018-inch nitinol wire as the reference point of the previously placed wire (yellow arrow heads). A distal perfusion catheter (6- or 7-Fr. sheath) was inserted antegrade and advanced safely into the mid-SFA. d The distal perfusion catheter was attached to the side port of the arterial cannula using 6-inch extension tubing with an intervening three-way stopcock

underwent fasciotomy, 3 received surgical thrombectomy, and 4 underwent surgical amputation of the distal lower limb implanted with ECMO. Limb ischemia was less frequent in the DPC group than in the No-DPC group ( $2.1 \%$ vs. $8.2 \% ; p=0.047)$. The incidences of major bleeding ( $8.3 \%$ vs. $4.5 \% ; p=0.228)$, thrombotic events (5.2\% vs. $9.7 \% ; p=0.211)$, and catheter-related complications $(24.0 \%$ vs. $19.4 \% ; p=0.405)$ were not different between the two groups. The rate of successful ECMO weaning was greater in the DPC group than in the NoDPC group $(79.2 \%$ vs. $61.9 \% ; p=0.005)$, and the DPC group had a lower tendency of in-hospital mortality than the No-DPC group (38.5\% vs. 50.7\%; $p=0.067)$ (Table 2 ).

\section{Fluoroscopy-guided distal perfusion and predictors} on lower limb ischemia

Of the 96 patients in the DPC group, 61 (63.5\%) underwent DPC insertion under fluoroscopic guidance (Table 1). Fluoroscopy-guided DPC group had a numerically low incidence of catheter-related complication including limb ischemia, cannular site bleeding, and thrombotic event compared to no fluoroscopy-guided DPC group (Table 2). Furthermore, the incidence of limb ischemia tended to be lower in the fluoroscopy-guided DPC group than in the No-DPC group $(p=0.057)$. We performed multivariable logistic regression analysis to identify predictors of limb ischemia in patients 
Table 1 Baseline and procedural characteristics

\begin{tabular}{|c|c|c|c|c|c|}
\hline & \multicolumn{3}{|c|}{ DPC group $(n=96)$} & \multirow[t]{2}{*}{ No-DPC group $(n=134)$} & \multirow{2}{*}{$\begin{array}{l}p \text { value DPC } \\
\text { versus No-DPC }\end{array}$} \\
\hline & $\begin{array}{l}\text { Fluoroscopy- } \\
\text { guided }(n=61)\end{array}$ & $\begin{array}{l}\text { No fluoroscopy- } \\
\text { guided }(n=35)\end{array}$ & $p$ value & & \\
\hline Age (years) & $55.2 \pm 16.7$ & $55.7 \pm 16.2$ & 0.143 & $58.5 \pm 13.7$ & 0.106 \\
\hline Gender (male) & $39(63.9)$ & $20(57.1)$ & 0.735 & $89(66.4)$ & 0.439 \\
\hline Body mass index $\left(\mathrm{kg} / \mathrm{m}^{2}\right)$ & $23.0 \pm 3.1$ & $25.0 \pm 3.9$ & $<0.001$ & $25.6 \pm 3.9$ & $<0.001$ \\
\hline Diabetes mellitus & $16(26.2)$ & $10(28.6)$ & 0.260 & $46(34.3)$ & 0.243 \\
\hline Hypertension & $22(36.1)$ & $10(28.6)$ & 0.790 & $51(38.1)$ & 0.462 \\
\hline Dyslipidemia & $11(18.0)$ & $2(5.7)$ & 0.016 & $9(6.7)$ & 0.083 \\
\hline Current smoker & $13(21.3)$ & $12(34.3)$ & 0.959 & $29(21.6)$ & 0.438 \\
\hline Chronic kidney disease & $4(6.6)$ & $2(5.7)$ & 0.688 & $11(8.2)$ & 0.576 \\
\hline Peripheral vascular disease & $2(3.3)$ & $0(0)$ & 0.670 & $3(2.2)$ & 0.936 \\
\hline Previous MI & $10(16.4)$ & $7(20.0)$ & 0.396 & $29(21.6)$ & 0.462 \\
\hline Previous PCI & $9(14.8)$ & $7(20.0)$ & 0.217 & $30(22.4)$ & 0.285 \\
\hline Previous CABG & $1(1.6)$ & $1(2.9)$ & 0.136 & $9(6.7)$ & 0.104 \\
\hline Previous CVA & $5(8.5)$ & $2(5.7)$ & 0.858 & $10(7.5)$ & 0.961 \\
\hline Clinical presentation & & & 0.002 & & 0.061 \\
\hline Ischemic cardiomyopathy & $32(52.5)$ & $10(28.6)$ & & $58(43.3)$ & \\
\hline Non-ischemic cardiomyopathy & $13(21.3)$ & $5(14.3)$ & & $21(15.7)$ & \\
\hline Septic shock & $0(0)$ & $6(17.1)$ & & $4(3.0)$ & \\
\hline Refractory arrhythmia & $8(13.1)$ & $1(2.9)$ & & $4(3.0)$ & \\
\hline Other causes & $8(13.1)$ & $13(37.1)$ & & $47(35.1)$ & \\
\hline Purpose of ECMO implantation & & & 0.035 & & 0.121 \\
\hline Bridge to recovery & $49(80.3)$ & $32(91.4)$ & & $122(91.0)$ & \\
\hline Bridge to transplantation & $12(19.7)$ & $3(8.6)$ & & $12(9.0)$ & \\
\hline ECPR & $24(39.3)$ & $17(48.6)$ & 0.002 & $84(62.7)$ & 0.003 \\
\hline Initial ECMO pump flow (L/min) & $3.0 \pm 0.8$ & $3.3 \pm 0.5$ & 0.722 & $3.1 \pm 1.1$ & 0.729 \\
\hline Operating site of ECMO & & & $<0.001$ & & $<0.001$ \\
\hline Intensive care unit & $0(0)$ & $21(60.0)$ & & $31(23.1)$ & \\
\hline Catheterization laboratory room & $56(91.8)$ & $0(0)$ & & $33(24.6)$ & \\
\hline Emergency room & $4(6.6)$ & $7(20.0)$ & & $27(20.1)$ & \\
\hline Operating room & $0(0)$ & $4(11.4)$ & & $17(12.7)$ & \\
\hline Others & $1(1.6)$ & $3(8.6)$ & & $26(19.4)$ & \\
\hline Arterial catheter size (Fr.) & $15.3 \pm 0.7$ & $15.4 \pm 0.9$ & 0.061 & $15.3 \pm 0.8$ & 0.080 \\
\hline Venous catheter sized (Fr.) & $22.4 \pm 1.5$ & $21.9 \pm 0.7$ & 0.010 & $21.5 \pm 2.4$ & 0.019 \\
\hline Large arterial cannula & $10(16.4)$ & $9(25.7)$ & 0.055 & $41(30.6)$ & 0.066 \\
\hline \multicolumn{6}{|l|}{ During ECMO support } \\
\hline Anticoagulation therapy & $52(85.2)$ & $25(71.4)$ & 0.001 & $84(62.7)$ & 0.004 \\
\hline Left ventricular venting & $16(26.2)$ & $3(8.6)$ & 0.003 & $13(9.7)$ & 0.029 \\
\hline Distal perfusion & $61(100.0)$ & $35(100.0)$ & $<0.001$ & $21(15.7)$ & $<0.001$ \\
\hline Continuous renal replacement therapy & $18(29.5)$ & $16(45.7)$ & 0.177 & $53(39.6)$ & 0.524 \\
\hline Intra-aortic balloon pump & $2(3.3)$ & $1(2.9)$ & 0.696 & $6(4.5)$ & 0.602 \\
\hline Mechanical ventilation & $47(77.0)$ & $27(77.1)$ & 0.318 & $94(70.1)$ & 0.243 \\
\hline \multicolumn{6}{|l|}{ Laboratory findings } \\
\hline Creatinine (mg/dL) (just before ECMO insertion) & $1.4(1.0-1.54)$ & $1.2(0.8-1.4)$ & 0.391 & $1.3(0.9-1.9)$ & 0.779 \\
\hline Lactate (mmol/L) (just before ECMO insertion) & $4.9(2.8-9.2)$ & $5.7(2.0-10.4)$ & 0.051 & $5.3(2.1-10.1)$ & 0.683 \\
\hline Lactate (mmol/L) (24 h after ECMO insertion) & $1.9(1.4-3.1)$ & $2.2(1.1-4.9)$ & 0.300 & $2.1(0.0-3.9)$ & 0.700 \\
\hline Duration of ECMO support (day) & $3.4(2.1-7.5)$ & $4.0(2.0-6.3)$ & 0.013 & $2.0(1.0-5.0)$ & 0.052 \\
\hline Length of ICU stay (day) & $10.0(3.5-19.0)$ & $6.0(1.0-15.5)$ & 0.518 & $5.0(1.0-10.0)$ & 0.012 \\
\hline Length of hospital stay (day) & $27.0(14.0-73.0)$ & $24.0(7.5-49.8)$ & 0.271 & $14.0(5.0-34.0)$ & 0.030 \\
\hline
\end{tabular}

Values are mean \pm standard deviation, median (interquartile range), or $\mathrm{n}(\%)$

$C A B G$ coronary artery bypass grafting, CVA cerebrovascular accident, DPC distal perfusion catheter, ECPR extracorporeal cardiopulmonary resuscitation, ICU intensive care unit, $M /$ myocardial infarction, $P C l$ percutaneous coronary intervention, $E C M O$ extracorporeal membrane oxygenation

${ }^{a}$ We considered patient used $16-21-\mathrm{Fr}$. catheter as patient used large arterial catheter 
Table 2 Clinical outcomes and complications

\begin{tabular}{|c|c|c|c|c|c|}
\hline & \multicolumn{3}{|l|}{ DPC group $(n=96)$} & \multirow{2}{*}{$\begin{array}{l}\text { No-DPC group } \\
(n=134)\end{array}$} & \multirow{2}{*}{$\begin{array}{l}p \text { value DPC } \\
\text { versus No-DPC }\end{array}$} \\
\hline & $\begin{array}{l}\text { Fluoroscopy-guided } \\
(n=61)\end{array}$ & $\begin{array}{l}\text { No fluoroscopy-guided } \\
(n=35)\end{array}$ & $p$ value & & \\
\hline Limb ischemia & $1(1.6)$ & $1(2.9)$ & 0.688 & $11(8.2)$ & 0.047 \\
\hline Major bleeding & $5(8.2)$ & $3(8.6)$ & 0.949 & $6(4.5)$ & 0.228 \\
\hline Thrombotic event & $2(3.3)$ & $3(8.6)$ & 0.261 & $13(9.7)$ & 0.211 \\
\hline Catheter-related complication ${ }^{\mathrm{a}}$ & $12(19.7)$ & $11(31.4)$ & 0.194 & $26(19.4)$ & 0.405 \\
\hline Successful weaning from ECMO & $49(80.3)$ & $27(77.1)$ & 0.711 & $83(61.9)$ & 0.005 \\
\hline In-hospital mortality & $22(36.1)$ & $15(42.9)$ & 0.510 & $68(50.7)$ & 0.067 \\
\hline
\end{tabular}

Values are $n(\%)$

DPC distal perfusion catheter, ECMO extracorporeal membrane oxygenation

a Catheter-related complication was defined as a composite of limb ischemia, cannular site bleeding, and thrombotic event

undergoing VA-ECMO. Simultaneous DPC insertion (OR 0.13, 95\% CI $0.03-0.68, p=0.016$ ) and ICU stay $\geq 11$ days (OR $4.34,95 \%$ CI $1.26-14.97, p=0.020$ ) on model I, and fluoroscopy-guided simultaneous DPC insertion (OR 0.11, 95\% CI 0.01-0.98, $p=0.048$ ) and ICU stay $\geq 11$ days (OR 3.71, 95\% CI 1.12-12.32, $p=0.032$ ) on model II were significant prognostic factors for lower limb ischemia (Table 3).

\section{Discussion}

We investigated the association between the method and timing of distal perfusion and vascular complications, including limb ischemia, major bleeding, and thrombotic events, in patients undergoing VA-ECMO. Our main finding is that simultaneous DPC insertion at the time of primary ECMO cannulation reduced the incidence of lower limb ischemia. In the multivariable analysis, fluoroscopy-guided simultaneous insertion of DPC, duration of ECMO implantation $>5$ days, and use of a large arterial cannula (over $16 \mathrm{Fr}$.) were significant predictors of limb ischemia. In general, our findings correspond well with earlier studies that established an association between distal perfusion and adverse clinical outcomes [2, 9]. The present study showed for the first time that fluoroscopyguided DPC insertion via a contralateral approach might be a safe and effective strategy to prevent limb ischemia in femorally cannulated patients on VA-ECMO.

VA-ECMO implantation for patients with refractory cardiopulmonary failure is quick and convenient when using a percutaneous femoral approach, but limb ischemia and other catheter-related complications frequently develop due to partial luminal obstruction or injury to the common femoral artery or vein. Muehrcke et al. [10] reported an ischemia rate of 70\% in an ECMO population of 24 patients without DPC placement at the time of cannulation. Their cannulation protocol
Table 3 Predictors of lower limb ischemia

\begin{tabular}{llll}
\hline & Odds ratio & $\mathbf{9 5 \%} \mathbf{C l}$ & $\boldsymbol{p}$ value \\
\hline Model I & & & \\
Simultaneous DPC insertion & 0.13 & $0.03-0.68$ & 0.016 \\
Age $\geq 65$ years & 0.27 & $0.06-1.35$ & 0.111 \\
Male & 1.37 & $0.40-4.76$ & 0.618 \\
BMI $\geq 25 \mathrm{~kg} / \mathrm{m}^{2}$ & 0.46 & $0.13-1.66$ & 0.235 \\
Diabetes mellitus & 0.91 & $0.25-3.35$ & 0.891 \\
Clinical presentation & 0.77 & $0.52-1.14$ & 0.189 \\
ICU stay $\geq 11$ days & 4.34 & $1.26-14.97$ & 0.020 \\
Model II & & & \\
Fluoroscopy-guided DPC insertion & 0.11 & $0.01-0.98$ & 0.048 \\
Age $\geq 65$ years & 0.28 & $0.06-1.36$ & 0.114 \\
Male & 1.46 & $0.42-5.10$ & 0.554 \\
BMI $\geq 25 \mathrm{~kg} / \mathrm{m}^{2}$ & 0.48 & $0.14-1.70$ & 0.255 \\
Diabetes mellitus & 0.93 & $0.25-3.45$ & 0.910 \\
Clinical presentation & 0.73 & $0.49-1.10$ & 0.131 \\
ICU stay $\geq 11$ days & 3.71 & $1.12-12.32$ & 0.032 \\
\hline
\end{tabular}

Model I: adjusted with simultaneous DPC insertion, age $\geq 65$ years, male, $\mathrm{BMI} \geq 25 \mathrm{~kg} / \mathrm{m}^{2}$, diabetes mellitus, clinical presentation, and ICU stay $\geq 11$ days Model II: adjusted with fluoroscopy-guided simultaneous DPC insertion, age $\geq 65$ years, male, $\mathrm{BMI} \geq 25 \mathrm{~kg} / \mathrm{m}^{2}$, diabetes mellitus, clinical presentation, and ICU stay $\geq 11$ days

$B M I$ body mass index, $\mathrm{Cl}$ confidence interval, $D P C$ distal perfusion catheter, ICU intensive care unit

was modified to include simultaneous DPC placement, with noted improvement in limb salvage. Foley et al. [5] reported an ischemia rate of $21 \%$ in 58 patients without DPCs, although they found no difference in limb ischemia or mortality between prophylactic and expectant placement of a DPC. These findings strongly suggest that limb ischemia can be avoided in a large number of patients undergoing ECMO if the physician can safely insert a DPC. Additionally, Lamb et al. [2] reported that placement of a DPC at the time of cannulation and 
intensive monitoring of limb perfusion may decrease the incidence of ischemic complication. Ranney et al. [9] investigated the indication and timing of DPC placement and reported that DPC placement at the time of primary cannulation may lower the incidence of limb ischemia. However, both studies had a limited number of patients and focused only on the occurrence of complicated limb ischemia in ECMO patients; therefore, no definite conclusion can be drawn from these studies. The strength of our study is in the comparison of overall clinical outcomes and ECMO-related vascular complications, as well as limb ischemia, between two timings of DPC insertion using a large, dedicated ECMO registry.

In the real-world practice, additional procedures, like DPC insertion, could be harmful in critically ill patients who are vulnerable to bleeding or who had received anticoagulation therapy while on ECMO. Therefore, finding a method to insert the DPC that avoids bleeding complications caused by multiple needle thrusts would make it possible to avoid fatal complications in the lower limb. In the present study, DPCs were preferentially inserted in all VA-ECMO patients unless limited by technical considerations, typically an inability to cannulate the SFA, and no procedural-related limb complication occurred in patients treated with fluoroscopy-guided DPC insertion. Our findings suggest that simultaneous DPC insertion at the time of primary ECMO cannulation should be considered to prevent limb ischemia, and image-guided insertion methods, such as fluoroscopy, are more effective and safe.

\section{Study limitations}

This study has several limitations. First, its design was non-randomized, retrospective, and observational, which may have affected the results due to confounding factors. Second, the selection of treatment strategy for the cannulated limb was at the discretion of the operator and could have influenced the results by introducing bias. Third, the impact of limb ischemia on long-term outcomes and the influence of eventual distal perfusion in the No-DPC group were not assessed in this study. Fourth, patients undergoing simultaneous DPC insertion may be comparatively more stable to those who do not undergo the procedure. The DPC and No-DPC groups were different in baseline BMI, rate of ECPR, and operating site of ECMO in the present study. This might have influenced study outcomes and produced a higher rate of ECMO weaning in patients undergoing simultaneous DPC insertion. Finally, we did not compare our fluoroscopy-guided contralateral DPC strategy with previous methods such as ultrasound-guided DPC insertion or ipsilateral DPC insertion. Therefore, this method cannot be chosen with certainty as the best method of DPC insertion.

\section{Conclusion}

Simultaneous insertion of DPC at the time of primary ECMO cannulation using a femoral approach could prevent advanced limb ischemia. In particular, fluoroscopyguided DPC insertion via a contralateral approach can be considered as a new strategy for prevention of disastrous vascular complications.

\section{Abbreviations \\ DPC: distal perfusion catheter; SFA: superficial femoral artery; VA-ECMO: venoarterial extracorporeal membrane oxygenation.}

\section{Authors' contributions}

WJJ and JHY had full access to all of the data and take responsibility for the integrity of the data and the accuracy of the data analysis. WJJ, YHC, and JHY contributed to the study concept and design. All authors contributed to the acquisition, analysis, or interpretation of data. WJJ and JHY drafted the manuscript. WJJ, YHC, and JHY contributed to critical revision of the manuscript for important intellectual content. WJJ and JHY performed statistical analysis. SHC and JHY were responsible for study supervision. All authors gave final approval of the version to be published and agreed to be accountable for all aspects of the work, thereby ensuring that questions related to the accuracy or integrity of any part of the work are appropriately investigated and resolved. All authors read and approved the final manuscript.

\section{Author details \\ ${ }^{1}$ Division of Cardiology, Department of Internal Medicine, Samsung Chang- won Hospital, Sungkyunkwan University School of Medicine, Changwon, Republic of Korea. ${ }^{2}$ Department of Thoracic and Cardiovascular Surgery, Sam- sung Medical Center, Sungkyunkwan University School of Medicine, Seoul, Republic of Korea. ${ }^{3}$ Division of Cardiology, Department of Critical Care Medi- cine and Medicine, Heart Vascular Stroke Institute, Samsung Medical Center, Sungkyunkwan University School of Medicine, 81, Irwon-dong, Gangnam-gu, Seoul 135-710, Republic of Korea.}

\section{Acknowledgements}

None.

Competing interests

The authors declare that they have no competing interests.

Availability of data and materials

Not applicable.

Consent for publication

All authors have read the manuscript and approved its submission to Annals of Intensive Care.

\section{Ethics approval and consent to participate}

The local institutional review board of each participating hospital approved this study and waived the requirement for informed consent.

\section{Funding}

None.

\section{Publisher's Note}

Springer Nature remains neutral with regard to jurisdictional claims in published maps and institutional affiliations.

Received: 23 July 2018 Accepted: 20 October 2018

Published online: 29 October 2018 


\section{References}

1. Kar B, Gregoric ID, Basra SS, Idelchik GM, Loyalka P. The percutaneous ventricular assist device in severe refractory cardiogenic shock. J Am Coll Cardiol. 2011;57:688-96.

2. Lamb KM, DiMuzio PJ, Johnson A, Batista P, Moudgill N, McCullough M, et al. Arterial protocol including prophylactic distal perfusion catheter decreases limb ischemia complications in patients undergoing extracorporeal membrane oxygenation. J Vasc Surg. 2017;65:1074-9.

3. Bisdas T, Beutel G, Warnecke G, Hoeper MM, Kuehn C, Haverich A, et al. Vascular complications in patients undergoing femoral cannulation for extracorporeal membrane oxygenation support. Ann Thorac Surg. 2011:92:626-31.

4. Huang SC, Yu HY, Ko WJ, Chen YS. Pressure criterion for placement of distal perfusion catheter to prevent limb ischemia during adult extracorporeal life support. J Thorac Cardiovasc Surg. 2004;128:776-7.

5. Foley PJ, Morris RJ, Woo EY, Acker MA, Wang GJ, Fairman RM, et al. Limb ischemia during femoral cannulation for cardiopulmonary support. J Vasc Surg. 2010:52:850-3.
6. Aziz F, Brehm CE, El-Banyosy A, Han DC, Atnip RG, Reed AB. Arterial complications in patients undergoing extracorporeal membrane oxygenation via femoral cannulation. Ann Vasc Surg. 2014;28:178-83.

7. Zimpfer D, Heinisch B, Czerny M, Hoelzenbein T, Taghavi S, Wolner E, et al. Late vascular complications after extracorporeal membrane oxygenation support. Ann Thorac Surg. 2006;81:892-5.

8. Park TK, Yang JH, Jeon K, Choi SH, Choi JH, Gwon HC, et al. Extracorporeal membrane oxygenation for refractory septic shock in adults. Eur J Cardiothorac Surg. 2015:47:e68-74.

9. Ranney DN, Benrashid E, Meza JM, Keenan JE, Bonadonna D, Mureebe $L$, et al. Vascular complications and use of a distal perfusion cannula in femorally cannulated patients on extracorporeal membrane oxygenation. ASAIO J. 2018;64:328-33.

10. Muehrcke DD, McCarthy PM, Stewart RW, Seshagiri S, Ogella DA, Foster RC, et al. Complications of extracorporeal life support systems using heparin-bound surfaces. The risk of intracardiac clot formation. J Thorac Cardiovasc Surg. 1995;110:843-51.

\section{Submit your manuscript to a SpringerOpen ${ }^{\circ}$ journal and benefit from:}

- Convenient online submission

- Rigorous peer review

- Open access: articles freely available online

- High visibility within the field

- Retaining the copyright to your article 